\title{
Locally produced estrogen promotes fetal rat metatarsal bone growth; an effect mediated through increased chondrocyte proliferation and decreased apoptosis
}

\author{
A S Chagin ${ }^{1}$, D Chrysis ${ }^{1}$, M Takigawa ${ }^{2}$, E M Ritzen ${ }^{1}$ \\ and $\mathbf{L}$ Sävendahl ${ }^{\mathbf{1}}$ \\ ${ }^{1}$ Pediatric Endocrinology Unit, Department of Woman and Child Health, Karolinska Institute, Karolinska University Hospital, SE-171 76 Stockholm, Sweden \\ ${ }^{2}$ Department of Biochemistry and Molecular Dentistry, Okayama University Graduate School of Medicine and Dentistry, Okayama, Japan \\ (Requests for offprints should be addressed to A S Chagin; Email: andrei.chagin@ki.se)
}

\begin{abstract}
The importance of estrogens for the regulation of longitudinal bone growth is unequivocal. However, any local effect of estrogens in growth plate cartilage has been debated. Recently, several enzymes essential for estrogen synthesis were shown to be expressed in rat growth plate chondrocytes. Local production of $17 \beta$-estradiol (E2) has also been demonstrated in rat costal chondrocytes. We aimed to determine the functional role of locally produced estrogen in growth plate cartilage. The human chondrocyte-like cell line HCS-2/8 was used to study estrogen effects on cell proliferation $\left({ }^{3} \mathrm{H}\right.$-labeled thymidine uptake) and apoptosis (cell death detection ELISA kit). Chondrocyte production of E2 was measured by RIA and organ cultures of fetal rat metatarsal bones were used to study the effects of estrogen on longitudinal growth rate. We found that significant amounts of E2 were produced by HCS-2/8 chondrocytes $\left(64 \cdot 1 \pm 5 \cdot 3 \mathrm{fmol} / 3\right.$ days $/ 10^{6}$ cells $)$. The aromatase inhibitor
\end{abstract}

letrozole $(1 \mu \mathrm{M})$ and the pure estrogen receptor antagonist ICI $182,780(10 \mu \mathrm{M})$ inhibited proliferation of HCS-2/8 chondrocytes by $20 \% \quad(P<0 \cdot 01)$ and almost $50 \%$ $(P<0 \cdot 001)$, respectively. Treatment with ICI 182,780 $(10 \mu \mathrm{M})$ increased apoptosis by $228 \%(P<0 \cdot 05)$. Cotreatment with either caspase-3 or pan-caspase inhibitors completely blocked ICI 182,780-induced apoptosis $(P<0 \cdot 001$ vs ICI 182,780 only). Moreover, both ICI $182,780(10 \mu \mathrm{M})$ and letrozole $(1 \mu \mathrm{M})$ decreased longitudinal growth of fetal rat metatarsal bones after 7 days of culture $(P<0 \cdot 01)$. In conclusion, our data clearly show that chondrocytes endogenously produce E2 and that locally produced estrogen stimulates chondrocyte proliferation and protects from spontaneous apoptosis. In addition, longitudinal growth is promoted by estrogens locally produced within the epiphyseal growth plate.

Journal of Endocrinology (2006) 188, 193-203

\section{Introduction}

Longitudinal bone growth occurs at the growth plate, a thin layer of chondrocytes between the epiphysis and the metaphysis of long bones, through a process called endochondral ossification, in which cartilage is first formed and then replaced by bone tissue.

The processes of chondrocyte proliferation and differentiation are regulated by many hormones and growth factors. Among these, sex steroids are of crucial importance, especially during puberty (Grumbach \& Auchus 1999). A few rare individuals, one male with an inactivating mutation in the estrogen receptor $\alpha(E R \alpha)$ (Smith et al. 1994) and a few males and females with aromatase enzyme deficiency (Morishima et al. 1995, Maffei et al. 2004), have clearly established that estrogens are important for the pubertal growth spurt and for epiphyseal closure.
Similarly, experiments with estrogen receptor knockout mice have demonstrated the importance of both ER $\alpha$ and estrogen receptor- $\beta(E R \beta)$ in the regulation of longitudinal bone growth (Vidal et al. 2000, Chagin et al. 2004). In addition, both $\mathrm{ER} \alpha$ and $\mathrm{ER} \beta$ are expressed in growth plate cartilage from different species, including rat, rabbit and human (Kusec et al. 1998, Nilsson et al. 1999, 2002, 2003), suggesting that estrogens can act directly on growth plate chondrocytes. In spite of the well known growth promoting effects of estrogens in humans and animals in vivo, data from in vitro experiments are inconclusive. In fact, there are reports of estrogen stimulating (Somjen et al. 1989, 1991, Maor et al. 1999), inhibiting (Nasatzky et al. 1993, Schwartz et al. 1997) or having no effect (Rodd et al. 2004) on chondrocyte proliferation.

Besides the gonads, several other tissues can produce estrogens, for instance adipose tissue (Folkerd et al. 1982), 
osteoblasts (Bruch et al. 1992), vascular endothelial cells and aortic smooth muscle cells (Sasano et al. 1999) as well as several sites in the brain (Naftolin et al. 1975). The process of local estrogen synthesis and action within the cells of peripheral target tissues is often referred to as intracrinology. In this process, active synthesis of sex steroids occur from inactive precursor steroids, such as dehydroepiandrosterone (DHEA) and its sulfate (DHEA$\mathrm{S})$, secreted in large amounts by the adrenal glands (Labrie et al. 1988). In fact, plasma DHEA-S levels in adult men and women are 1000 to 10000 times higher than those of estradiol, thus providing a large reservoir for conversion into estrogens in peripheral tissues. There are several enzymes involved in this conversion. The most important are aromatase p450, type I and II 17 $\beta$-hydoxysteroid dehydrogenase (17 $\beta-H S D)$ and steroid sulfatase (STS), for review see Simpson (2003). Intriguingly, all enzymes needed for the conversion of DHEA to estrogen, such as p450 aromatase, type I and II 17 $\beta$-HSD and STS, have recently been demonstrated in the rat tibia growth plate (Van Der Eerden et al. 2002). These findings open the possibility that locally produced estrogen could play a role in the regulation of chondrocyte proliferation, differentiation and/or apoptosis.

This study was designed to determine the role of locally produced estrogen in the regulation of growth plate cartilage. For this purpose, we chose two different experimental models, a human chondrocyte cell line HCS-2/8 and an organ culture model of fetal rat metatarsal bones.

\section{Materials and Methods}

\section{Materials}

Recombinant human IGF-1 was kindly supplied by Pharmacia Corp. 17 $\beta$-estradiol (E2), dexamethasone, BSA and $\beta$-glycerophosphate were purchased from Sigma. Letrozole was kindly provided by Novartis AB. ICI 182,780 was purchased from Tocris Inc. (Bristol, UK). Anti IGF-I (H-70), IGF-II (H-103), p450 aromatase CYP 19 (C-16) and IGF-I receptor beta subunit (IGF-IR $\beta$; C-20) antibodies were all purchased from Santa Cruz Biotech. Inc (Santa Cruz, CA, USA). Anti ER $\beta$ antibody was purchased from Upstate (Lake Placid, NY, USA). For immunohistochemistry, we used anti-ER $\alpha$ (MC-20) antibody from Santa Cruz Biotech. Inc. and for Western blot analysis, ER $\alpha$ antibody from StressGen Biotech Inc (Victoria, BC, Canada). PBS, DMEM/F12 medium, FBS, Trypsin-EDTA solution and gentamycin were all from Invitrogen Inc. Charcoal treated fetal bovine serum (CTS) was from HyClone (Logan, UT, USA). Ascorbic acid was from ICN Corp. (Aurora, OH, USA).

\section{Cell culture}

The human chondrocyte-like cell line HCS-2/8, which is of male origin (Takigawa et al. 1989) was used as a model of human growth plate chondrocytes. The cells have several markers of growth plate chondrocytes, such as expression of collagen type II, and have the ability to form columns and to differentiate into hypertrophic chondrocytes expressing alkaline phosphatase and collagen type X (Takigawa et al. 1989). The cells were cultured in DMEM/F12 mixture medium supplemented with 20\% fetal bovine serum (FBS) and $20 \mu \mathrm{g} / \mathrm{ml}$ gentamycin at $37^{\circ} \mathrm{C}$ under $5 \% \mathrm{CO}_{2}$ in humidified atmosphere. Before experiments, cells were trypsinized, counted and plated in 96-well plates $(20000$ cells per well, for experiments shown in Fig. 2 and 3; $2 \times 10^{6}$ cells per $25 \mathrm{~cm}^{2}$ flask for detection of E2 in the culture medium). After $72 \mathrm{~h}$ of recovery, cells were washed with PBS and then cultured in DMEM/F12 medium (no phenol red) with different concentrations of serum, steroids and/or IGF-I added.

\section{Metatarsal organ culture}

Fetal rat metatarsal rudiments were collected from 20-day embryos (De Luca et al. 2001). The three middle metatarsals were dissected out from each hind leg. After dissection, bones were transferred to 24-well plates, one bone per well and cultured in $1 \mathrm{ml}$ phenol red-free DMEM/F12 medium supplemented with $0 \cdot 2 \%$ endotoxin-free fraction V BSA, $1 \mathrm{mM} \beta$-glycerophosphate, $0.05 \mathrm{mg} / \mathrm{ml}$ ascorbic acid and $20 \mu \mathrm{g} / \mathrm{ml}$ gentamycin at $37^{\circ} \mathrm{C}$ under $5 \% \mathrm{CO}_{2}$ in humidified atmosphere. Medium was changed every 2-3 days. Bones were measured as previously described (Martensson et al. 2004) at days 0, 2, 5, 7, 12 and 19 of culture. Metatarsal growth is expressed as a percentage of the length at the day of dissection (day $0=$ baseline). Treatment with IGF-I and steroids was started 4-6 h after dissection. All isolated bones (usually 30 to 40 per experiment) were pooled and then randomly divided into the different treatment groups ( 3 to 5 bones per group). Each experiment was repeated at least 3 times. The study was approval by the local ethical committee at Karolinska Institute (Stockholm, Sweden).

\section{${ }^{3}$ H-thymidine incorporation}

Cells in 96-well plates were labeled for the last $2.5 \mathrm{~h}$ of culture with ${ }^{3} \mathrm{H}$-thymidine (Amersham Pharmacia Biotech), $2.5 \mu \mathrm{Ci}$ per $\mathrm{ml}$, and then harvested (Soder et al. 1992). Incorporated radioactivity was measured by a Beckman scintillation spectrophotometer (Beckman Instruments, Fullerton, CA, USA) as counts per min (c.p.m.). For each treatment, triplicate or quadruplicate cell cultures were used and each experiment was repeated 3-8 times. 
Analysis of E2 production

The cell culture medium was changed 3 days prior to assay. Additionally, the same medium was added to cell-free dishes as a control. At the day of assay, conditioned medium was collected and cells were counted. E2 in 20\% FBS-supplemented medium was measured by RIA without prior extraction (PerkinElmer, Turku, Finland). The amount of E2 in the blank (cell free, 20\% FBS or 1\% CTS supplemented medium) was subtracted. The amount of E2 produced was normalized per 3 days and per number of cells. The 1\% CTS-supplemented medium was first partially vacuum dried, then precipitated with ethylene acetate, dried and then dissolved in ethanol in order to reach detectable concentrations. The concentration of E2 was measured by RIA (PerkinElmer, Turku, Finland). The limit of detection for the estradiol assay was $4.8 \mathrm{pmol} / 1$ and the intra-assay coefficient of variation was $4 \%$. The cross reactivity (at the 50\% displacement level) with estrone was $0 \cdot 75 \%$, estriol $0 \cdot 40 \%$, testosterone $<0 \cdot 01 \%$, and for DHEA-S < $0.001 \%$.

\section{Immunohistochemistry}

Fetal rat metatarsal bones were cultured for 7 days, fixed in $4 \%$ formaldehyde, paraffin embedded and $5 \mu \mathrm{m}$-thick sections were obtained. Immunohistochemistry was performed exactly as previously described (Nilsson et al. 2002). Dilution of primary antibodies was as follows: anti-ER $\alpha$ antibody 1:500 (MC-20, Santa Cruz), antiER $\beta$ antibody 1:1000 (Upstate), anti-CYP19 aromatase P450 1:100 (C-16, Santa Cruz), anti-IGF-I antibody 1:300 (H-70, Santa Cruz), anti IGF-II antibody 1:100 (H-103, Santa Cruz), anti-IGF-IR $\beta$ antibody 1:150 (C20, Santa Cruz). As a control, antibodies were preincubated for 1 hour at room temperature with $10 \times$ $(\mathrm{w} / \mathrm{w})$ excess of the corresponding blocking peptide (MC-20, C-16 and C-20 antibodies) or IGF-I (H-70 and H-103 antibodies).

\section{Reverse transcription-PCR}

Extraction of total RNA from $\mathrm{HCS}-2 / 8$ proliferative chondrocytes was performed using the Qiagen RNeasy mini kit. The following pairs of primers were used to generate the respective cDNAs: human IGF-I, 5'AAATCAGCAGTCTTCCAACC-3' and 5'-CTTCTG GGTCTTGGGCATGT-3' (396 bp), human IGF-II 5'CTGGAGACGTACTGTGCTAC-3' and 5'-GGTGTT TAAAGCCAATCGAT-3' (547 bp), human type X collagen, 5'-AGCCAGGGTTGCCAGGACCA-3' and 5'-TTTTCCCACTCCAGGAGGGC-3' (387 bp). The $\beta$-actin gene, 5'-CACACTGTGCCCATCTACGA-3' and 5'-GTTTCATGGATGCCACAGGA-3' (349 bp), was used as a control to normalize the data. The annealing temperature was $56{ }^{\circ} \mathrm{C}$ for IGF-I (35 cycles), $58{ }^{\circ} \mathrm{C}$ for
IGF-II (30 cycles), $56{ }^{\circ} \mathrm{C}$ for collagen type X (35 cycles) and $58^{\circ} \mathrm{C}$ for $\beta$-actin (25 cycles). The PCR-products were separated by electrophoresis in a $2 \%$ agarose gel with ethidium bromide $(15 \mu \mathrm{g} / 10 \mathrm{ml})$. RNA from $\mathrm{HCS}-2 / 8$ chondrocytes, cultured for 18 days under differentiation conditions, was used as a positive control for type $\mathrm{X}$ collagen.

\section{Western blot}

Cells, growing in logarithmic phase of growth were washed twice with ice-cold PBS, scraped in $2 \times$ loading buffer $(250 \mathrm{mM}$ Tris $\mathrm{pH}$ 6.8, 4\% SDS, 10\% glycerol, $0 \cdot 006 \%$ bromophenol blue, $2 \% \quad \beta$-mercaptoethanol), boiled for $5 \mathrm{~min}$ and sonicated on ice. Twenty $\mu \mathrm{g}$ of protein per lane was subjected to SDS-PAGE and than transferred to an Immobilon-P membrane (Amersham Pharmacia Biotech). The filters were blocked in 5\% blocking agent (Amersham Pharmacia Biotech) and subsequently incubated with the first antibody (anti-ER $\alpha$, 1:4000 dilution; anti-ER $\beta, 1: 1000$ dilution; anti-CYP19 aromatase $\mathrm{P} 450,1: 500$ dilution; anti-IGF-IR $\beta, 1: 1000$ dilution) and then the appropriate secondary HRPconjugated antibody. Detection was performed with ECL+Plus (Amersham Pharmacia Biotech) according to the manufacturer's instructions. Protein concentrations were measured by spectrophotometer using a Protein Assay Kit (Bio-Rad Laboratories) before gel electrophoresis. Equal loading of total proteins was confirmed by Coomasie Blue staining after the experiment.

\section{Bromodeoxyuridine labeling (BrdU labeling)}

BrdU-labeling was performed as previously described (Martensson et al. 2004). Briefly, fetal rat metatarsal bones were cultured for 7 days with/without $10 \mu \mathrm{M}$ ICI 182,780. Two and a half hours prior to fixation, the DMEM/F12 medium was changed to MEM medium, supplemented with BrdU labeling reagent (1:200 dilution of labeling reagent, Cell Proliferation Kit RPN20; Amersham Biosciences). The bones were then fixed and $5 \mu \mathrm{m}$-thick paraffin-embedded sections were obtained. Detection of BrdU-positive cells were performed as recently described (Martensson et al. 2004). The level of proliferation was expressed as number of BrdU-positive cells per $\mathrm{mm}^{2}$ surface area.

\section{TUNEL}

Apoptotic cells were identified by terminal deoxynucleotidyl transferase (TdT)-mediated deoxy-UTP nick end labeling (TUNEL) immunohistochemistry according to instructions for the TdT-FragEL DNA fragmentation kit, (Oncogene Research, Boston, MA, USA) with the modification that sections were treated with $5 \mu \mathrm{g} / \mathrm{ml}$ proteinase $\mathrm{K}$ for $10 \mathrm{~min}$ (Martensson et al. 2004). Sections 


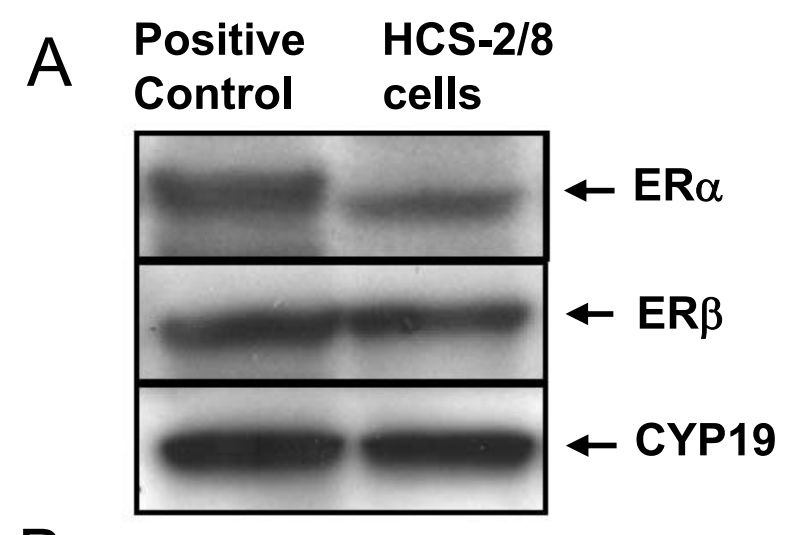

B
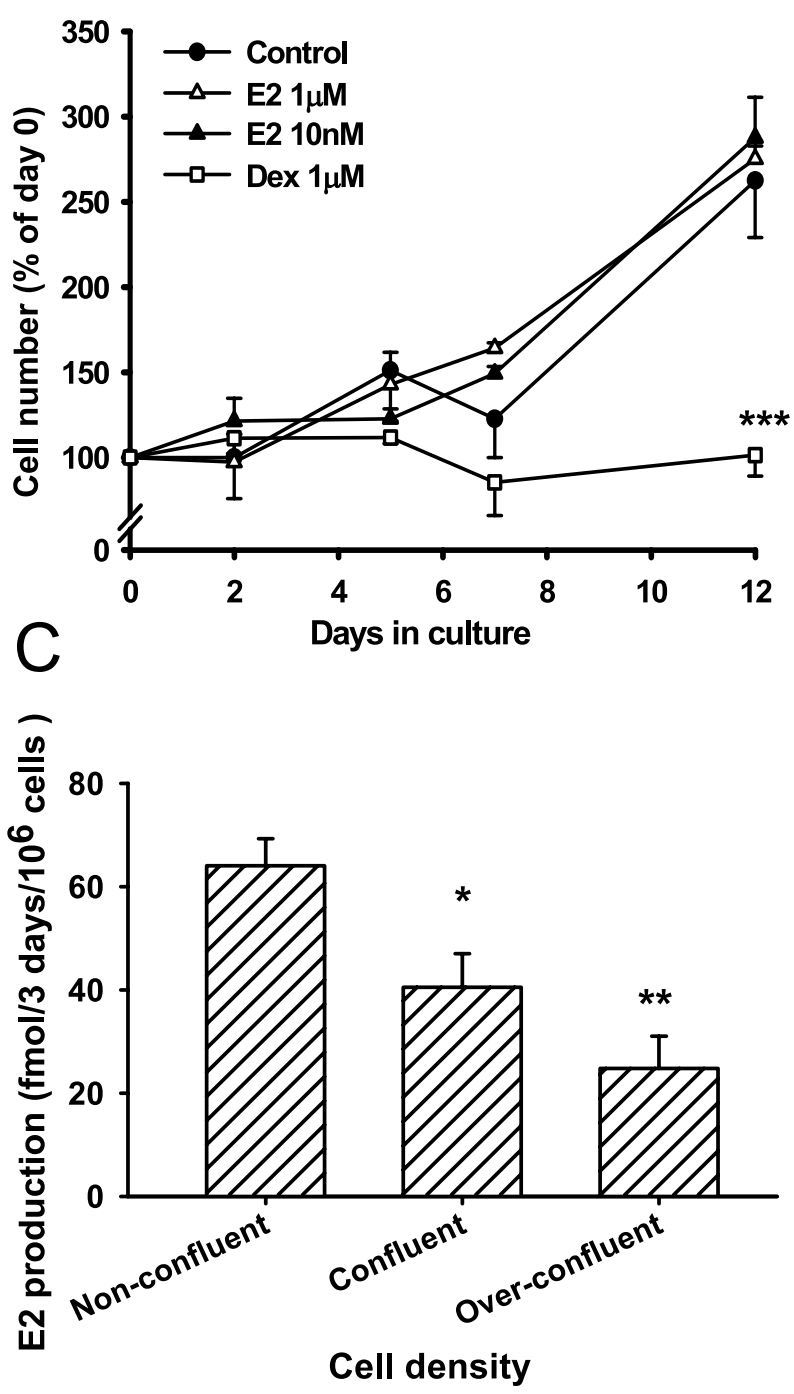

Journal of Endocrinology (2006) 188, 193-203 were counterstained with Alcian Blue, dehydrated, and mounted. For each group, the number of apoptotic cells was determined in five metatarsals, and at least 2 sections were assessed for each bone. The number of apoptotic chondrocytes was counted and expressed per $\mathrm{mm}^{2}$ surface area. After pre-treatment of sections with distilled water instead of TdT, all cells were negative, whereas treatment with DNase labeled all cells.

\section{Cell death detection ELISA}

Apoptosis was studied by measuring the cytoplasmic histone-associated DNA fragments (mono- and oligonucleasomes) by photometric enzyme-immunoassay (cell death detection ELISA; Roche Diagnostics GmbH) exactly as recently described (Chrysis et al. 2005). Three samples were analyzed for each experiment, which was repeated 4 times.

\section{Statistical analysis}

One-way ANOVA followed by Student-NewmanKeuls method was applied for all statistical analysis if not otherwise stated. $P$-values $<0 \cdot 05$ were considered statistically significant.

\section{Results}

\section{Role of estrogen in HCS-2/8 human chondrocytes}

HCS-2/8 human chondrocytes expressed ER- $\alpha$, ER $\beta$ and aromatase P450 (Fig. 1A). To investigate any effect of exogenous estrogen on cell proliferation, HCS-2/8 chondrocytes were cultured for 12 days with E2 added at

Figure 1 Local production of estrogen by HCS-2/8 chondrocytes and expression of estrogen receptors, which lack response to exogenous E2. (A) HCS-2/8 cells express ER $\alpha, E R \beta$ and aromatase P450 (CYP19) as detected by Western immunoblotting (see Material and Methods). MCF-7 breast cancer cells were used as positive controls for $\mathrm{ER} \alpha$ and rat testis for ER $\beta$ and aromatase P450. (B) HCS-2/8 cells did not respond to E2 (10 nM and $1 \mu \mathrm{M})$, while dexamethasone $(1 \mu \mathrm{M})$ decreased cell proliferation. Cells were cultured in the presence of $5 \%$ CTS and counted after 0,2 , 5,7 and 12 days of culture. Data represent the mean \pm S.E.M. for at least 3 independent experiments ( ${ }^{* *} P<0.001$ vs control). (C) HCS-2/8 cells locally synthesized E2. Cultures of HCS-2/8 chondrocytes reaching three different densities (non-confluent - 3 days in culture confluent -10 days in culture and over-confluent -17 days in culture) were rinsed with PBS and then fresh culture medium supplemented with 20\% FBS was applied for 3 days. The medium was then collected and the levels of E2 were analyzed by RIA (see Material and Methods). The concentration of E2 in culture medium without cells (20\% FBS, DMEM/F12) was analyzed in parallel $(22 \cdot 4 \pm 3 \cdot 3 \mathrm{pmol} / \mathrm{l})$ and subtracted from the conditioned medium. The production of E2 was normalized per cell number. Data represent the mean \pm S.E.M. for 3 independent experiments. ${ }^{*} P<0 \cdot 05$; ${ }^{*} P<0 \cdot 01$ vs non-confluent cells. 
different concentrations in culture media containing no serum or charcoal treated serum (CTS; $0 \cdot 2 \%, 1 \%$ or $5 \%$ ). Independent of what culture media used, cell number (data for media containing 5\% CTS and $10 \mathrm{nM}$ and $1 \mu \mathrm{M}$ E2 are shown in Fig. 1B) and thymidine incorporation were unaffected by exogenous E2 at concentrations ranging between $0.1 \mathrm{nM}$ and $1 \mu \mathrm{M}$ (data not shown, see also Fig 2B for $100 \mathrm{pM}$ E2 in 1\% CTS). IGF-I $(100 \mathrm{ng} / \mathrm{ml})$ increased cell proliferation 3- to 4-fold, an effect which was unchanged if the cells were co-treated with IGF-I $(100 \mathrm{ng} / \mathrm{ml})$ plus E2 $(1 \mathrm{nM}-1 \mu \mathrm{M})$ (data not shown). Dexamethasone $(1 \mu \mathrm{M})$ significantly decreased cell proliferation (Fig. 1B).

As HCS-2/8 chondrocytes did not respond to exogenous E2, we hypothesized that the cells might synthesize estrogen by themselves and that this could be of physiological importance. Indeed, we found that HCS-2/8 cells produced $64 \cdot 1 \pm 5 \cdot 3 \mathrm{fmol} / 3$ days $/ 10^{6}$ cells of E2 (Fig. 1C). Interestingly, the production of estrogen was dependent on the stage of chondrocyte differentiation, being high in proliferative cells (non-confluent) and gradually decreasing in more differentiated confluent and over-confluent cell cultures $(P<0 \cdot 01$ between nonconfluent and over-confluent cultures, Fig. 1C). The chondrocyte differentiation in over-confluent cell cultures was confirmed by detection of collagen type $\mathrm{X}$ by RT-PCR (data not shown). The aromatase inhibitor letrozole $(10 \mu \mathrm{M})$ decreased E2 production by HCS-2/8 chondrocytes from $64 \cdot 1 \pm 5.3 \mathrm{fmol}$ to $24.5 \pm 6.7 \mathrm{fmol} / 3$ days $/ 10^{6}$ cells $(P<0 \cdot 01$ by $t$-test). HCS $-2 / 8$ chondrocytes still produced small amounts of E2 (0.234 $\pm 0 \cdot 071 \mathrm{fmol} / 3$ days $/ 10^{6}$ cells) when cultured under steroid depleted conditions (1\% CTS, phenol red free medium).

\section{Role of locally produced estrogen in HCS-2/8 chondrocytes}

To study any physiological relevance of endogenously produced estrogen, HCS $-2 / 8$ chondrocytes were treated with an aromatase inhibitor, letrozole, or with a pure non-selective anti-estrogen, ICI 182,780. Cell proliferation was significantly decreased in $\mathrm{HCS}-2 / 8$ cells treated with either letrozole or ICI 182,780 (Fig 2A). Moreover, E2 $(100 \mathrm{pM})$ was able to restore cell proliferation when added in combination with letrozole (completely for $1 \mu \mathrm{M}$ and partially for $10 \mu \mathrm{M}$ letrozole; Fig 2B). Treatment with ICI 182,780 not only inhibited cell proliferation but also induced apoptosis in a dose-dependent way when cultured for 48 h (Fig. 3). Further studies showed that ICI $182,780(10 \mu \mathrm{M})$ induced apoptosis already after $24 \mathrm{~h}$ $(130 \pm 10 \%)$, being maximal after $48 \mathrm{~h}(228 \pm 30 \%$, $P<0 \cdot 05$ vs control) and then slightly lower after $72 \mathrm{~h}$ of treatment $(170 \pm 19 \%, P<0 \cdot 05$ vs control). To further support these results and also to understand the apoptotic pathways involved in ICI 182,780-induced apoptosis, caspase inhibition experiments were performed. Both caspase-3 and pan-caspase inhibitors completely
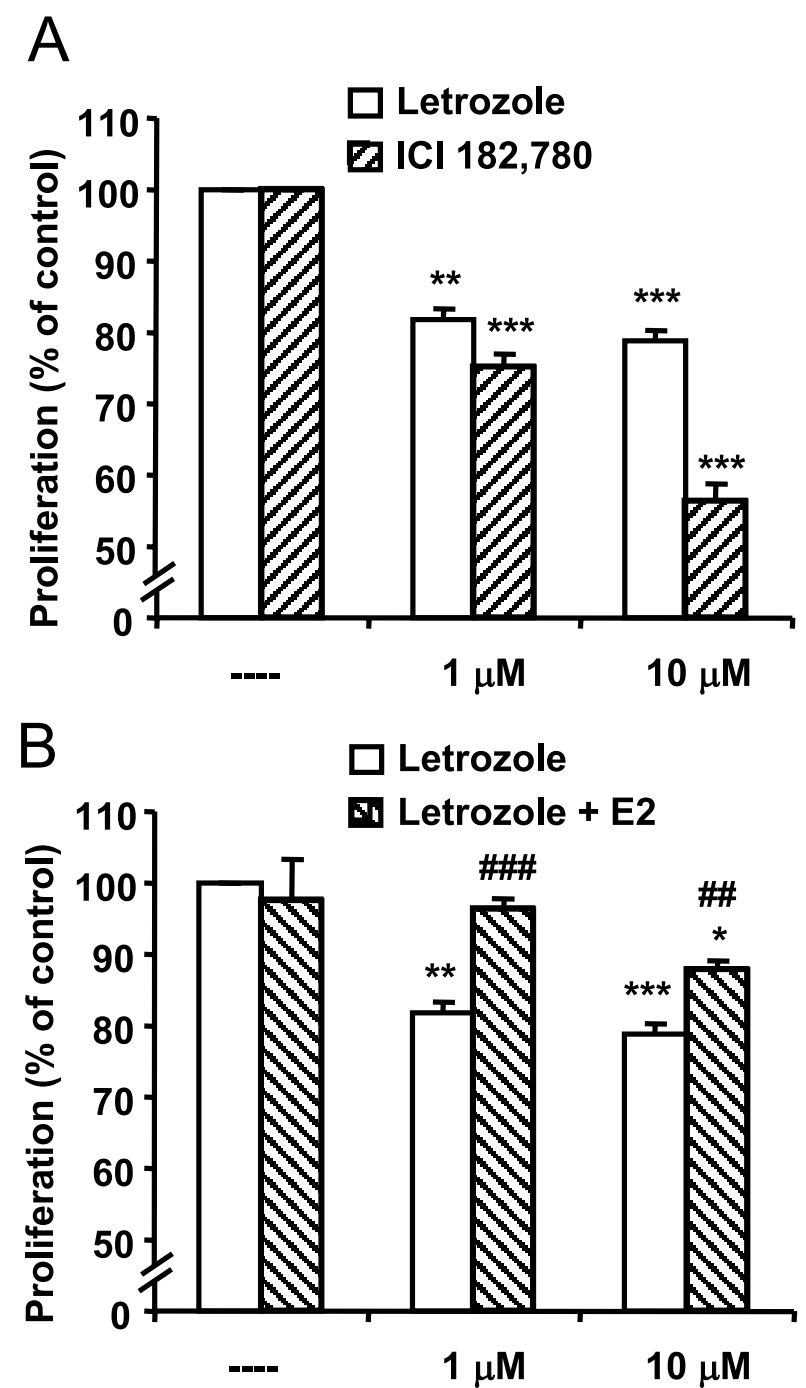

Figure 2 Locally synthesized E2 promotes HCS-2/8 cell proliferation. (A) Both letrozole (aromatase blocker) and $\mathrm{ICI}$ 182,780 (non-selective ER-blocker) inhibited HCS-2/8 cell proliferation when added for $48 \mathrm{~h}$ in the presence of $1 \%$ charcoal treated serum (CTS). (B) E2 (100 pM) restored letrozole-mediated inhibition of HCS-2/8 cell proliferation, when added in combination with letrozole $(1 \mu \mathrm{M}$ and $10 \mu \mathrm{M})$ for $48 \mathrm{~h}$ in the presence of $1 \%$ CTS. Cell proliferation was analyzed by ${ }^{3} \mathrm{H}$-thymidine incorporation (see Material and Methods). Data represent the mean \pm S.E.M. for at least 3 independent experiments. ${ }^{*} P<0 \cdot 05,{ }^{* *} P<0 \cdot 01,{ }^{* * *} P<0 \cdot 001$ vs untreated cells; ${ }^{\# \#} P<0 \cdot 01$,

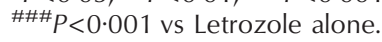

blocked ICI 182,780-induced apoptosis (Fig 3), showing that it is a caspase dependent apoptosis. As another evidence of caspase involvement, we found that cleavage of the proteins PARP and fodrin occurred after treatment of HCS-2/8 cells with $10 \mu \mathrm{M}$ ICI 182,780 for $72 \mathrm{~h}$ (data not shown). 


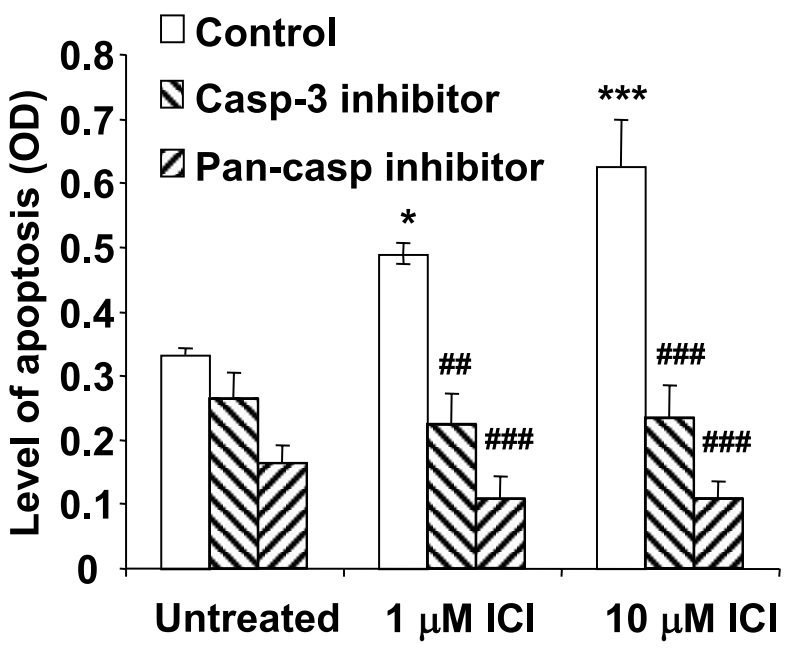

Figure 3 Caspase-dependent apoptosis induced by ICl 182,780. HCS-2/8 cells were treated for $48 \mathrm{~h}$ with ICI $182,780(1 \mu \mathrm{M}$ or $10 \mu \mathrm{M})$ with/without caspase-3 $(50 \mu \mathrm{M})$ or pan-caspase $(50 \mu \mathrm{M})$ inhibitors added ( $1 \%$ CTS in all medium). The level of apoptosis was analyzed by a cell death detection ELISA Kit (see Material and Methods). Data represent the mean \pm S.E.M. for at least 3 independent experiments. ${ }^{*} P<0 \cdot 05,{ }^{* * *} P<0 \cdot 001$ vs untreated

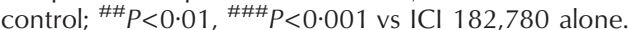

\section{Locally produced estrogen maintains fetal rat metatarsal} bone growth

Fetal rat metatarsal bones expressed $\operatorname{ER} \alpha, \operatorname{ER} \beta$ and aromatase P450 (Fig. 4, upper, middle and lower panels, respectively). The expression of ER $\alpha$ and $\operatorname{ER} \beta$ was widely distributed and mainly associated with resting and proliferative chondrocytes (Fig. 4, upper and middle panels). However, the expression of aromatase $\mathrm{P} 450$ was associated with hypertrophic chondrocytes (Fig. 4, lower panels).

Treatment with E2 at $1 \mu \mathrm{M}$ (Fig. 5A) or $10 \mathrm{nM}$ (data not shown) did not affect longitudinal growth at any time point when cultured in serum free medium for up to 19 days. When analyzed separately, neither female nor male metatarsals responded to E2 (data not shown). However, metatarsal bone growth was increased by IGF-I $(100 \mathrm{ng} / \mathrm{ml}$; Fig. 5A) and decreased by dexamethasone $(1 \mu \mathrm{M}$; Fig. $5 \mathrm{~A})$.

Longitudinal growth of cultured fetal rat metatarsal bones was significantly inhibited when cultured in the presence of the aromatase inhibitor letrozole $(1 \mu \mathrm{M})$,

Figure 4 Expression of $E R \alpha, E R \beta$ and aromatase P450 in fetal rat metatarsal bones. The bones were cultured for 7 days, then fixed and paraffin embedded. The expression patterns of ER $\alpha$ (upper panels) and ER $\beta$ (middle panels) and aromatase P450 (CYP19; lower panels) were analyzed by immunohistochemistry in $5 \mu \mathrm{M}$-thick sections (see Material and Methods). Immuno-positive cells for both ER $\alpha$ and ER $\beta$ were commonly detected in resting ( $r$ ) and proliferative $(p)$ chondrocytes, while immuno-positive cells for aromatase P450 were detected in hypertrophic (h) chondrocytes (arrows show a few typical cells).

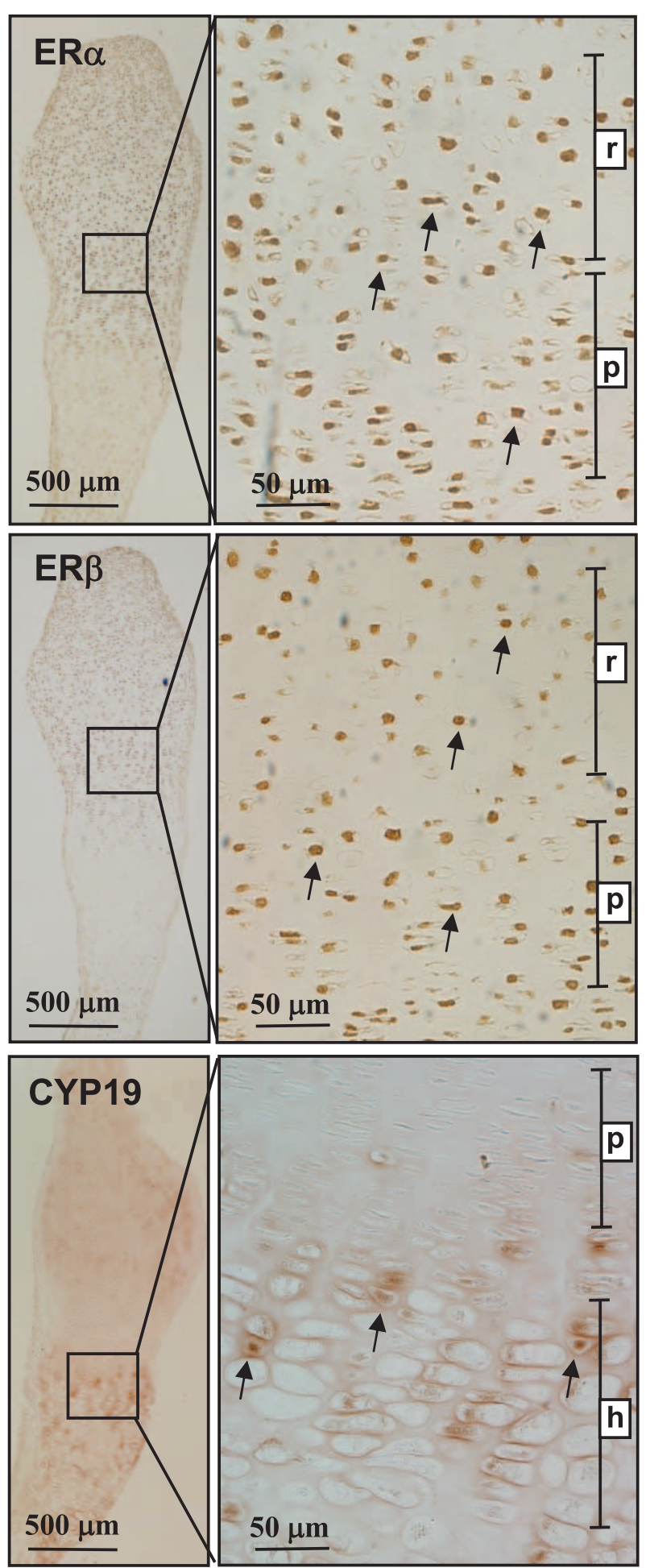

www.endocrinology-journals.org 

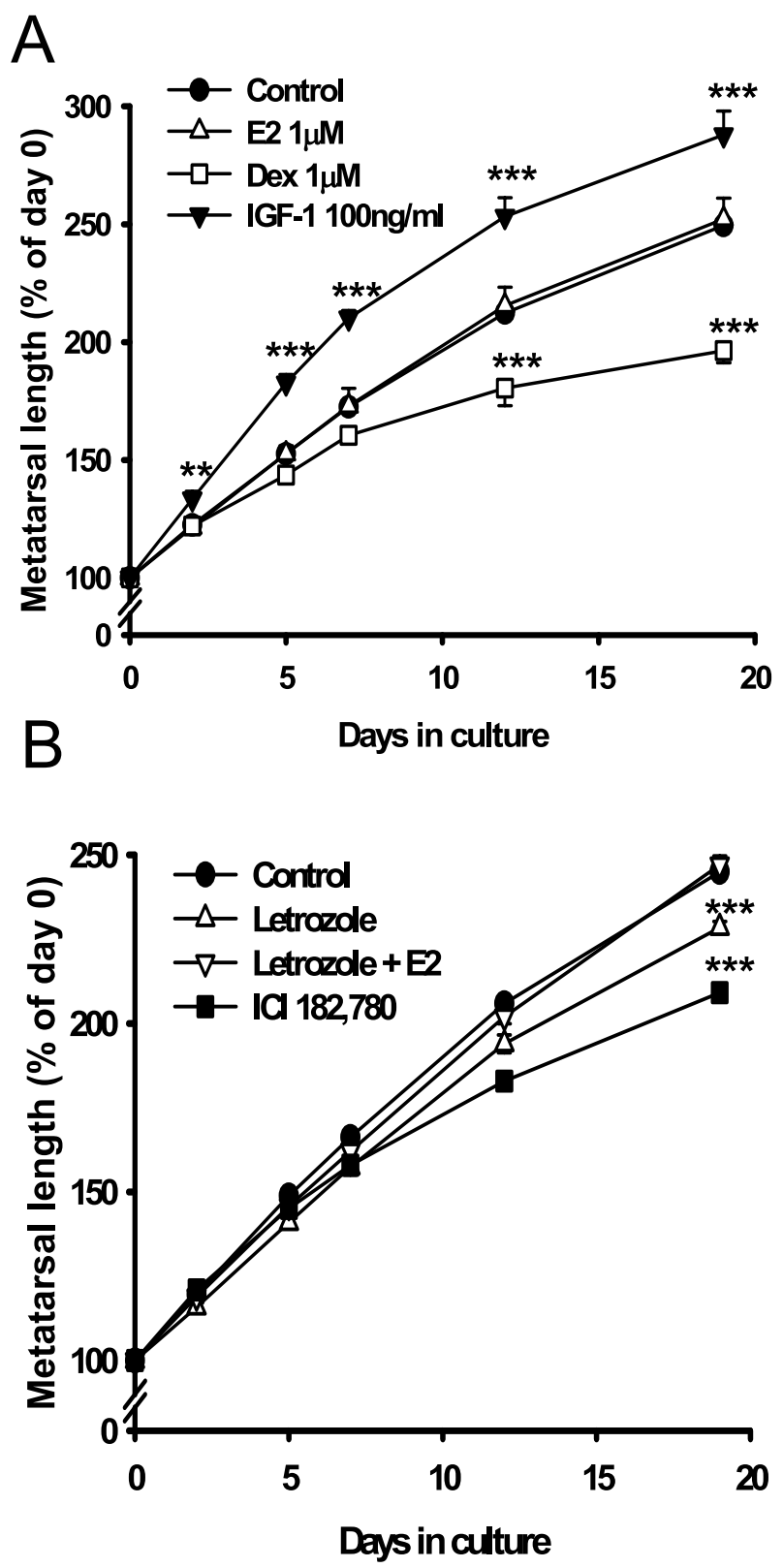

Figure 5 Effect of locally produced estrogen on longitudinal growth. Fetal rat metatarsal bones were cultured for 19 days in the presence of E2 $(1 \mu \mathrm{M})$, dexamethasone $(1 \mu \mathrm{M})$, or IGF-I $(100 \mathrm{ng} / \mathrm{ml})(\mathrm{A})$, or in the presence of letrozole $(1 \mu \mathrm{M})$, letrozole plus estrogen $(10 \mathrm{nM})$ or $\mathrm{ICl} 182,780(10 \mu \mathrm{M})(\mathrm{B})$. At days $0,2,5$, 7,12 and 19, the lengths of the metatarsal bones were measured (see Material and Methods). Data represent the mean \pm S.E.M. for at least 3 independent experiments. ${ }^{*} P<0 \cdot 01$ and ${ }^{* * *} P<0 \cdot 001$ vs control.

which blocks the production of estradiol or the pure non-selective anti-estrogen, ICI 182,780 $(10 \mu \mathrm{M})$, which efficiently blocks signaling through $\mathrm{ER} \alpha$ and $\mathrm{ER} \beta$ (Fig. 5B). The growth retardation was significant already after 7 days of culture $(P<0 \cdot 01$ vs control for both

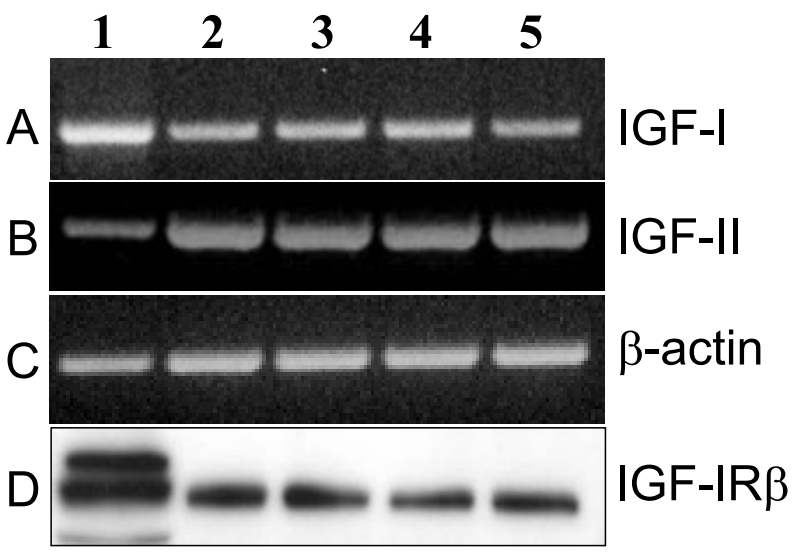

Figure 6 Effect of estrogen on IGF-I, IGF-II and IGF-IR $\beta$ expression in HCS- $2 / 8$ cells. HCS-2/8 cells were cultured for $48 \mathrm{~h}$ in $1 \% \mathrm{CTS}$ in the presence of vehicle $(0 \cdot 1 \%$ ethanol, lane 2$)$, E2 $(10 \mathrm{nM}$, lane 3), letrozole $(10 \mu \mathrm{M}$, lane 4$)$ or $\mathrm{ICl} 182,780(10 \mu \mathrm{M}$, lane 5). Human testis was used as a positive control (lane 1). Expression of IGF-I (A), IGF-II (B) and $\beta$-actin (C) was analyzed by RT-PCR and expression of IGF-IR $\beta$ (D) was analyzed by Western immunoblot as described in the Material and Methods.

letrozole and ICI). E2 restored letrozole-induced growth retardation to control levels (Fig. 5B). Detailed analysis of proliferation and apoptotic indices within metatarsal chondrocytes revealed that blocking of estrogen receptors with ICI 182,780 $(10 \mu \mathrm{M})$ was associated with decreased chondrocyte proliferation compared with control bones $\left(170 \pm 13\right.$ versus $277 \pm 38$ cells per $\mathrm{mm}^{2}$, respectively; $P<0 \cdot 05)$ and increased apoptosis $(55 \cdot 2 \pm 4 \cdot 2$ versus $33 \cdot 9 \pm$ 1.9 TUNEL-positive cells per $\mathrm{mm}^{2}$, respectively; $\left.P<0 \cdot 01\right)$.

\section{Cross-talk between estrogens and IGF-I system}

In order to study any cross-talk between the local estrogen and the IGF system, we analyzed the expression of IGF-I, IGF-II and the IGF-I receptor beta subunit (IGF-IR $\beta$ ). As shown in Fig. 6, exogenous E2, letrozole and ICI 182,780 were all unable to affect the expression of IGF-I, IGF-II and IGF-IR $\beta$ in HCS- $2 / 8$ cells. Immunohistochemical localization of IGF-I, IGF-II and IGF-IR $\beta$ within fetal rat metatarsal bones revealed that IGF-I is mainly localized within the resting zone, IGF-II mainly in late proliferative chondrocytes and IGF-IR $\beta$ in prehypertrophic and early hypertrophic chondrocytes (Fig. 7, left column, upper, middle and lower panels, respectively; and data not shown). Pre-incubation of the IGF-I and IGF-II antibodies with IGF-I completely abrogated IGF-I staining but did not affect IGF-II positive cells (Fig. 7, right column, upper and middle panels, respectively). Preincubation of the IGF-IR $\beta$ antibody with the corresponding peptide abrogated IGF-IR $\beta$ staining (Fig. 7, right column, lower panel). After culturing fetal rat metatarsal bones in the presence of ICI 182,780, we found a relative decrease of the intensity of the IGF-I, IGF-II 


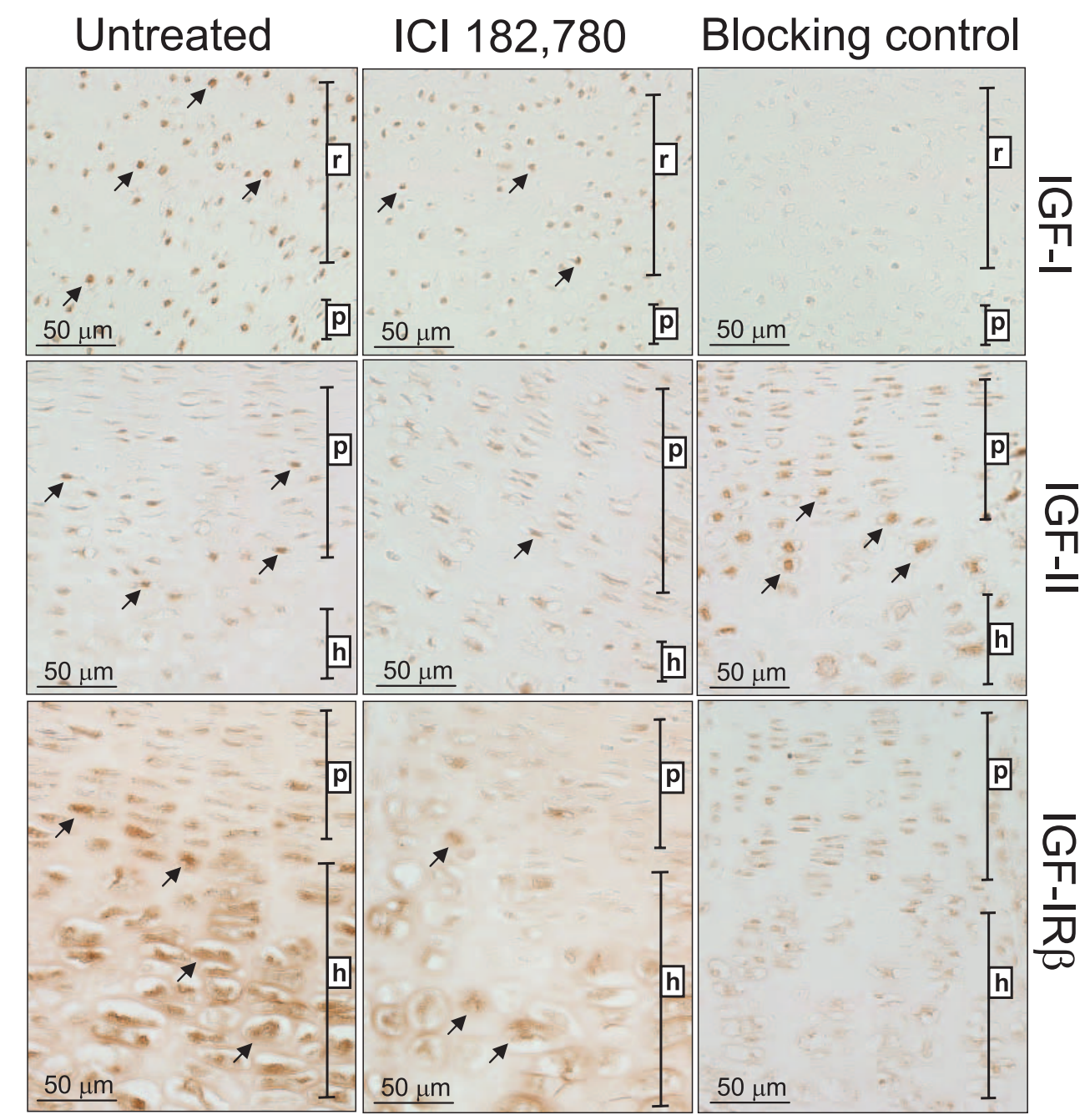

Figure 7 Effect of estrogen on IGF-I, IGF-II and IGF-IR $\beta$ expression in fetal rat metatarsal bones. Fetal rat metatarsal bones were cultured for 7 days in presence of vehicle $(0 \cdot 1 \%$ ethanol, left column) or $\mathrm{ICl}$ $182,780(10 \mu \mathrm{M}$, middle column). Expression patterns of IGF-I (upper panels), IGF-II (middle panels), and IGF-IR $\beta$ (lower panels) were analyzed by immunohistochemistry in $5 \mu \mathrm{M}$-thick sections (see Material and Methods). Blocking experiments (right column) were performed by pre-incubating of anti-IGF-I or anti-IGF-II antibodies with IGF-I and anti-IGF-IR $\beta$ antibodies with corresponding peptide as indicated in the Material and Methods (arrows show a few typical cells).

and IGF-IR $\beta$ immunostaining (Fig. 7, middle column, upper, middle and lower panels, respectively).

\section{Discussion}

We here show that estrogen, locally produced by growth plate chondrocytes, promotes longitudinal growth of fetal rat metatarsal bones. In addition, we demonstrate that endogenously produced estrogen has the capacity to promote chondrocyte proliferation and protect from programmed cell death.
The possibility of intracrine actions of estrogen within the epiphyseal growth plate has been well discussed (Van Der Eerden et al. 2003) and supported by several recent reports showing that chondrocytes are able to synthesize estrogen in vitro and in vivo (Oz et al. 2001, Sylvia et al. 2002, Van Der Eerden et al. 2002). P450 aromatase activity has been demonstrated in human (Oz et al. 2001) and rat (Van Der Eerden et al. 2002) growth plate cartilage. It should be emphasized that aromatase expression was mainly detected in adolescent humans and pubertal animals but very weak activity and expression of aromatase was detected before sexual maturation 
(Van Der Eerden et al. 2002). Interestingly, our observation of P450 aromatase expression in hypertrophic chondrocytes of fetal rat metatarsal bones is in line with several in vivo studies in different species (Oz et al. 2001, Van Der Eerden et al. 2002, Eshet et al. 2004). Several key enzymes needed for estrogen synthesis, including STS and $17 \beta-H S D$, has been demonstrated in rat growth plate cartilage (Van Der Eerden et al. 2002). Moreover, rat costal chondrocytes have been shown to synthesize estrogen (Sylvia et al. 2002). Our finding that HCS-2/8 chondrocytes endogenously produce estrogen is in line with those observations. Considering the poor vascularization of the growth plate, it can be assumed that the intracellular concentrations of the ligand are mainly dependent on its local production. Our finding that the amounts of estrogen produced by proliferative and hypertrophic chondrocytes in cell cultures are different, opens the possibility that estrogen synthesis is also regulated within the growth plate. This observation together with the previously described hormone- (Sylvia et al. 2002) and age-dependent (Van Der Eerden et al. 2002) regulation of estrogen synthesis within chondrocytes suggests physiological importance of intracrine estrogen action.

To understand the physiological role of locally produced estrogen within the growth plate, we blocked local estrogen synthesis by an aromatase inhibitor, letrozole, and estrogen receptors by the pure non-selective estrogen antagonist ICI 182,780. These experiments clearly show that endogenously produced estrogen stimulates chondrocyte proliferation and also longitudinal growth of fetal rat metatarsal bones. These data are in line with the recent observation that letrozole inhibits longitudinal growth velocity in boys (Wickman et al. 2001). Additionally, it is very well known that estrogen is able to stimulate longitudinal growth in humans (reviewed by Juul (2001). The mechanism behind this phenomenon is not clear, although low-dose estrogen treatment increases serum GH and IGF-I, which may contribute to the pubertal growth spurt (Juul 2001). Patients with growth hormone insensitivity do have a detectable pubertal growth spurt (Laron et al. 1980, 1993), which suggests that sex steroids also have a direct growth stimulatory effect which is independent of the $\mathrm{GH} / \mathrm{IGF}$-axis. In rodents, in contrast to humans, estrogen has a well known inhibitory effect on longitudinal growth. Treatment of mice with letrozole increases tibia length and epiphyseal growth plate height (Eshet et al. 2004). However, the effect was accompanied by an 8 -fold increase in serum GH and a 6-fold increase in serum testosterone, which most likely reflects the systemic actions of the letrozole treatment. Indeed, $\mathrm{GH}$ is a well known stimulator of longitudinal bone growth. Interestingly, we recently showed that androgens can counteract the suppressive effect of estrogen on longitudinal growth (Tivesten et al. 2004). Altogether, these data suggest that letrozole stimulates longitudinal growth through systemic actions.
A direct proliferative effect of E2 on chondrocytes in vitro is well documented in literature (Somjen et al. 1989, 1991, Maor et al. 1999). However, estrogen has also been reported to inhibit chondrocyte proliferation (Nasatzky et al. 1993, Schwartz et al. 1997). Such a difference can be explained by the dose-dependent actions of estrogen. Indeed, it has been shown that at different concentrations of the ligand, estrogen receptors can exert different, often opposite, effects (Hall \& McDonnell 1999, Pettersson et al. 2000).

We here report the novel finding that endogenously produced estrogen has the capacity to protect chondrocytes from undergoing programmed cell death. This finding is important as apoptosis is known to play an important role in growth plate homeostasis (Chrysis et al. 2002). Although estrogen is well known to have antiapoptotic actions in other tissues (Contreras et al. 2002, Rau et al. 2003), it is not clear how estrogen affects chondrocyte cell death. Here, we demonstrate that the withdrawal of estrogen induces apoptosis in a caspasedependent manner. This observation suggests involvement of specific anti-apoptotic pathways in the protective function of estrogen. However, we can not exclude the possibility that ICI 182,780 can act not only as a pure estrogen receptor antagonist but also as a selective estrogen receptor modulator. Additional studies are needed to reveal the exact mechanisms of the anti-apoptotic actions of estrogens in chondrocytes.

Despite the wide distribution of estrogen receptors, we did not find any effect of estrogen when added to cultures of HCS-2/8 chondrocytes or fetal rat metatarsal bones. One possible explanation could be that endogenously produced estrogen constantly activates estrogen receptors and thereby prevents further actions of exogenous estrogen. Local chondrocyte production of estrogens may vary between different experimental models which could explain the previously conflicting reports of varying estrogen effects on chondrocyte proliferation. If local estrogen synthesis is low due to specific experimental circumstances externally added estrogen will be capable to stimulate chondrocyte proliferation. Local estrogen production may be affected by factors such as age, sex and concomitant hormonal treatment or culture conditions.

In summary, we demonstrate a role of estrogen, locally produced by chondrocytes, in the normal regulation of growth plate cartilage. This endogenously produced estrogen maintains chondrocyte proliferation and protects cells from spontaneous apoptosis and thereby facilitates longitudinal growth. Our findings support the proposed intracrine actions of estrogen in growth plate cartilage.

\section{Acknowledgements}

This study was supported by the Swedish Research Council, Sällskapet Barnavård, Stiftelsen Frimurare 
Barnhuset i Stockholm, HKH Kronprinsessan Lovisas förening för Barnasjukvård, Wera Ekströms Stiftelse, and an unrestricted grant from Pfizer AB. We thank Yvonne Löfgren for excellent technical support. The authors declare that there is no conflict of interest that would prejudice the impartiality of this scientific work.

\section{References}

Bruch HR, Wolf L, Budde R, Romalo G \& Schweikert HU 1992 Androstenedione metabolism in cultured human osteoblast-like cells. Journal of Clinical Endocrinology and Metabolism 75 101-105.

Chagin AS, Lindberg MK, Andersson N, Moverare S, Gustafsson JA, Savendahl L \& Ohlsson C 2004 Estrogen receptor-beta inhibits skeletal growth and has the capacity to mediate growth plate fusion in female mice. Journal of Bone Mineral Research 19 72-77.

Chrysis D, Nilsson O, Ritzen EM \& Savendahl L 2002 Apoptosis is developmentally regulated in rat growth plate. Endocrine Journal 18 271-278.

Chrysis D, Zaman F, Chagin AS, Takigawa M \& Savendahl L 2005 Dexamethasone induces apoptosis in proliferative chondrocytes through activation of caspases and suppression of the Akt-phosphatidylinositol 3'-kinase signaling pathway. Endocrinology 146 1391-1397.

Contreras JL, Smyth CA, Bilbao G, Young CJ, Thompson JA \& Eckhoff DE 200217 beta-Estradiol protects isolated human pancreatic islets against proinflammatory cytokine-induced cell death: molecular mechanisms and islet functionality. Transplantation 74 1252-1259.

de Luca F, Barnes KM, Uyeda JA, De-Levi S, Abad V, Palese T, Mericq V \& Baron J 2001 Regulation of Growth Plate Chondrogenesis by Bone Morphogenetic Protein-2. Endocrinology 142 430-436.

Eshet R, Maor G, Ben Ari T, Ben Eliezer M, Gat-Yablonski G \& Phillip M 2004 The aromatase inhibitor letrozole increases epiphyseal growth plate height and tibial length in peripubertal male mice. Journal of Endocrinology 182 165-172.

Folkerd EJ, Reed MJ \& James VH 1982 Oestrogen production in adipose tissue from normal women and women with endometrial cancer in vitro. Journal of Steroid Biochemistry 16 297-302.

Grumbach MM \& Auchus RJ 1999 Estrogen: consequences and implications of human mutations in synthesis and action. Journal of Clinical Endocrinology and Metabolism 84 4677-4694.

Hall JM \& McDonnell DP 1999 The estrogen receptor beta-isoform $(\mathrm{ER} \beta)$ of the human estrogen receptor modulates ERalpha transcriptional activity and is a key regulator of the cellular response to estrogens and antiestrogens. Endocrinology 140 5566-5578.

Juul A 2001 The effects of oestrogens on linear bone growth. Human Reproduction Update 7 303-313.

Kusec V, Virdi AS, Prince R \& Triffitt JT 1998 Localization of estrogen receptor-alpha in human and rabbit skeletal tissues. Journal of Clinical Endocrinology and Metabolism 83 2421-2428.

Labrie C, Belanger A \& Labrie F 1988 Androgenic activity of dehydroepiandrosterone and androstenedione in the rat ventral prostate. Endocrinology 123 1412-1417.

Laron Z, Sarel R \& Pertzelan A 1980 Puberty in Laron type dwarfism. European Journal of Pediatrics 134 79-83.

Laron Z, Lilos P \& Klinger B 1993 Growth curves for Laron syndrome. Archives of Diseases in Children 68 768-770.

Maffei L, Murata Y, Rochira V, Tubert G, Aranda C, Vazquez M, Clyne CD, Davis S, Simpson ER \& Carani C 2004 Dysmetabolic syndrome in a man with a novel mutation of the aromatase gene: effects of testosterone, alendronate, and estradiol treatment. Journal of Clinical Endocrinology and Metabolism 89 61-70.

Maor G, Segev Y \& Phillip M 1999 Testosterone stimulates insulin-like growth factor-I and insulin-like growth
factor-I-receptor gene expression in the mandibular condyle-a model of endochondral ossification. Endocrinology 140 1901-1910.

Martensson K, Chrysis D \& Savendahl L 2004 Interleukin-1 beta and TNF-alpha act in synergy to inhibit longitudinal growth in fetal rat metatarsal bones. Journal of Bone Mineral Research 19 1805-1812.

Morishima A, Grumbach MM, Simpson ER, Fisher C \& Qin K 1995 Aromatase deficiency in male and female siblings caused by a novel mutation and the physiological role of estrogens. Journal of Clinical Endocrinology and Metabolism 80 3689-3698.

Naftolin F, Ryan KJ, Davies IJ, Reddy VV, Flores F, Petro Z, Kuhn M, White RJ, Takaoka Y \& Wolin L 1975 The formation of estrogens by central neuroendocrine tissues. Recent Progress in Hormone Research 31 295-319.

Nasatzky E, Schwartz Z, Boyan BD, Soskolne WA \& Ornoy A 1993 Sex-dependent effects of 17-beta-estradiol on chondrocyte differentiation in culture. Journal of Cell Physiology 154 359-367.

Nilsson LO, Boman A, Savendahl L, Grigelioniene G, Ohlsson C, Ritzen EM \& Wroblewski J 1999 Demonstration of estrogen receptor-beta immunoreactivity in human growth plate cartilage. Journal of Clinical Endocrinology and Metabolism 84 370-373.

Nilsson O, Abad V, Chrysis D, Ritzen EM, Savendahl L \& Baron J 2002 Estrogen receptor-alpha and -beta are expressed throughout postnatal development in the rat and rabbit growth plate. Journal of Endocrinology 173 407-414.

Nilsson O, Chrysis D, Pajulo O, Boman A, Holst M, Rubinstein J, Martin Ritzen E \& Savendahl L 2003 Localization of estrogen receptors-alpha and -beta and androgen receptor in the human growth plate at different pubertal stages. Journal of Endocrinology 177 319-326.

Oz OK, Millsaps R, Welch R, Birch J \& Zerwekh JE 2001 Expression of aromatase in the human growth plate. Journal of Molecular Endocrinology 27 249-253.

Pettersson K, Delaunay F \& Gustafsson JA 2000 Estrogen receptor beta acts as a dominant regulator of estrogen signaling. Oncogene 19 4970-4978.

Rau SW, Dubal DB, Bottner M, Gerhold LM \& Wise PM 2003 Estradiol attenuates programmed cell death after stroke-like injury. Journal of Neuroscience 23 11420-11426.

Rodd C, Jourdain N \& Alini M 2004 Action of Estradiol on Epiphyseal Growth Plate Chondrocytes. Calcified Tissue International 75 214-224.

Sasano H, Murakami H, Shizawa S, Satomi S, Nagura H \& Harada N 1999 Aromatase and sex steroid receptors in human vena cava. Endocrine Journal 46 233-242.

Schwartz Z, Finer Y, Nasatzky E, Soskolne WA, Dean DD, Boyan BD \& Ornoy A 1997 The effects of 17 beta-estradiol on chondrocyte differentiation are modulated by vitamin D3 metabolites. Endocrine 7 209-218.

Simpson ER 2003 Sources of estrogen and their importance. Journal of Steroid Biochemistry and Molecular Biology 86 225-230.

Smith EP, Boyd J, Frank GR, Takahashi H, Cohen RM, Specker B, Williams TC, Lubahn DB \& Korach KS 1994 Estrogen resistance caused by a mutation in the estrogen-receptor gene in a man. New England Journal of Medicne 331 1056-1061.

Soder O, Bang P, Wahab A \& Parvinen M 1992 Insulin-like growth factors selectively stimulate spermatogonial, but not meiotic, deoxyribonucleic acid synthesis during rat spermatogenesis. Endocrinology 131 2344-2350.

Somjen D, Weisman Y, Harell A, Berger E \& Kaye AM 1989 Direct and sex-specific stimulation by sex steroids of creatine kinase activity and DNA synthesis in rat bone. PNAS 86 3361-3365.

Somjen D, Weisman Y, Mor Z, Harell A \& Kaye AM 1991 Regulation of proliferation of rat cartilage and bone by sex steroid hormones. Journal of Steroid Biochemistry and Molecular Biology $40717-723$. 
Sylvia VL, Gay I, Hardin R, Dean DD, Boyan BD \& Schwartz Z 2002 Rat costochondral chondrocytes produce 17 beta-estradiol and regulate its production by 1 alpha, $25(\mathrm{OH})_{2} \mathrm{D}_{3}$. Bone 30 57-63.

Takigawa M, Tajima K, Pan HO, Enomoto M, Kinoshita A, Suzuki F, Takano Y \& Mori Y 1989 Establishment of a clonal humanchondrosarcoma cell line with cartilage phenotypes. Cancer Research 49 3996-4002.

Tivesten A, Moverare-Skrtic S, Chagin A, Venken K, Salmon P, Vanderschueren D, Savendahl L, Holmang A \& Ohlsson C 2004 Additive protective effects of estrogen and androgen treatment on trabecular bone in ovariectomized rats. Journal of Bone Mineral Research 19 1833-1839.

van der Eerden BC, van de Ven J, Lowik CW, Wit JM \& Karperien M 2002 Sex steroid metabolism in the tibial growth plate of the rat. Endocrinology 143 4048-4055. van der Eerden BC, Karperien M \& Wit JM 2003 Systemic and local regulation of the growth plate. Endocrine Reviews 24 782-801.

Vidal O, Lindberg MK, Hollberg K, Baylink DJ, Andersson G, Lubahn DB, Mohan S, Gustafsson JA \& Ohlsson C 2000 Estrogen receptor specificity in the regulation of skeletal growth and maturation in male mice. PNAS 97 5474-5479.

Wickman S, Sipila I, Ankarberg-Lindgren C, Norjavaara E \& Dunkel L 2001 A specific aromatase inhibitor and potential increase in adult height in boys with delayed puberty: a randomised controlled trial. Lancet 357 1743-1748.

Received 14 November 2005

Accepted 25 November 2005

Made available online as an Accepted Preprint

28 November 2005 